\title{
Management of multijoint stiffness of bilateral upper limbs secondary to heterotopic ossification: Case report and literature review
}

\author{
Hong-wei Min, MD; Ke-min Liu, MD; Xin-zuo Han, MD; Rui Gu, MD \\ School of Rehabilitation Medicine, Capital Medical University, Beijing, People’s Republic of China; Department of \\ Orthopedics and Rehabilitation, Beijing Charity Hospital, China Rehabilitation Research Center, Beijing, People's \\ Republic of China
}

\begin{abstract}
The management of heterotopic ossification (HO) is controversial. Although some reports have investigated assessment and surgical resection techniques for $\mathrm{HO}$ affecting one or more joints, the cases of multijoint stiffness secondary to $\mathrm{HO}$ are rare. This article describes a rare case of $\mathrm{HO}$ affecting both upper limbs of a 32-year-old man that severely interfered with activities of daily living. We present the rehabilitation management of this case and the functional outcome 1 to $2 \mathrm{yr}$ after excision of the ossific masses.
\end{abstract}

Key words: bilateral upper limbs, excision of ossific masses, functional outcome, heterotopic ossification, management, multijoint, prevention of recurrence, rehabilitation management, stiffness, surgical resection.

\section{INTRODUCTION}

Among the population of individuals with traumatic brain injury (TBI), the estimated prevalence of clinical heterotopic ossification (HO) is more than 20 percent [1], which can severely restrict range of motion (ROM) in the involved joints [1-3]. The effectiveness of pharmacological prophylaxis has not been irrefutably proven, and prophylactic irradiation runs a potential risk of malignancy $[1,4]$. A lack of consensus exists regarding the timing of excising of an ossific mass $[1,4]$. Although some studies have reported surgical excision of HO, few have elaborated on the functional outcomes of activities of daily living (ADLs) after surgery [5-6].
To the best of our knowledge, no cases of HO involving five joints of the bilateral upper limbs that required resection have been reported. The patient in the present report cannot carry out self-dressing, personal hygiene, and toiletry, even though he can ambulate. Due to the ankylosis of both upper limbs, the patient had slight difficulty maintaining his body balance. This article represents an original study of $\mathrm{HO}$ affecting multiple joints of the bilateral upper limbs requiring excision and rehabilitation management.

\section{CASE REPORT: METHODS AND RESULTS}

In June 2009, at the age of 28, the patient experienced a severe TBI in a motor vehicle accident. Extensive contusion and laceration of the left frontal, right frontal, and temporal lobes and corpus callosum were diagnosed, with a coma of 2 mo. The initial Glasgow Coma Scale score was 6. Upon regaining consciousness,

\footnotetext{
Abbreviations: $\mathrm{ADL}=$ activity of daily living, $\mathrm{HO}=$ heterotopic ossification, $\mathrm{ROM}=$ range of motion, $\mathrm{TBI}=$ traumatic brain injury.

*Address all correspondence to Ke-min Liu, MD; School of Rehabilitation Medicine, Capital Medical University, Beijing, People's Republic of China, 100068.

Email: keminlqliu@sina.com

http://dx.doi.org/10.1682/JRRD.2013.03.0073
} 
the patient complained of pain and restricted ROM in both shoulders, both elbows, and the left middle finger. Radiographs confirmed that $\mathrm{HO}$ affected these five joints.

The patient was presented to us 18 mo later. He could ambulate but his body balance control was poor, with rigid upper limbs and slight lower-limb spasticity. Both shoulders were stiff and fixed in $30^{\circ}$ abduction. Both elbows were also stiff; the left was fixed in $70^{\circ}$ flexion and the right in $50^{\circ}$ flexion. The proximal interphalangeal joint of the left middle finger was fixed in $90^{\circ}$ flexion. The motor strength of the shoulders, elbows, and left middle finger could not be ascertained due to muscle spasticity and ankylosis. The laboratory data were within normal limits.

Figures 1 to 4 show the location of $\mathrm{HO}$ in the five joints.

From December 2010 to December 2011, the patient underwent five operations with intervals of a few months between operations. Partial osteotomy of the HO was performed in the shoulders until the joint was sufficiently "free," but the HO in the elbows and finger was removed completely and normal passive ROM of the three joints was achieved intraoperatively. Wound drains were kept for 3 to $5 \mathrm{~d}$ depending on the amount of drainage. Active and passive ROM exercises were encouraged and started on the morning of the first postoperative day within tolerable pain under the care of a physiotherapist. In order to alleviate the spasticity in the limbs, manipulation techniques such as tapping, cold water compress, rubbing, and stretching were used to assist joint exercises. Oral indomethacin $(25 \mathrm{mg})$ was administered three times per day for 1 mo after each operation.

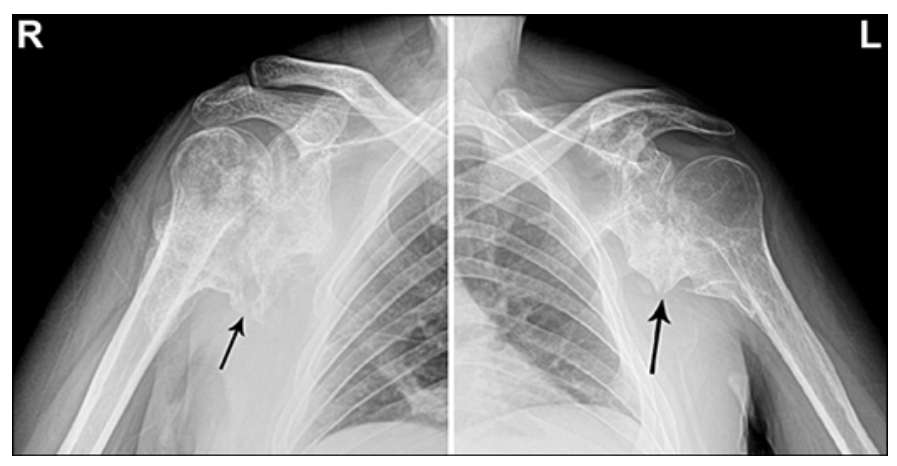

\section{Figure 1.}

Anteroposterior radiographies showing heterotopic ossification on inferomedial aspect of joints in both shoulders. $L=$ left, $R=$ right.
The last follow-up was performed 12 mo after the last operation and 24 mo after the first operation. The Table shows the ROM of the involved joints.

Despite the muscle spasticity, the patient could use his hands to reach his mouth, head, and perineum and self-dress, which were impossible prior to presenting to us. After liberating the stiff shoulders and elbows, the patient felt he could swing his arms rhythmically while walking. The patient reported that his balance control ability improved while walking. The patient and his parents were satisfied with improvement in ADLs. Radiographs of both upper limbs showed no recurrence of $\mathrm{HO}$ after surgery (Figure 5).

\section{DISCUSSION}

The pathophysiology and genetics that give rise to $\mathrm{HO}$ in patients with TBI are unclear. When HO occurs after TBI, both upper and lower limbs are affected. Hip is the most common joint affected by HO, followed by the elbow. TBI-HO of the shoulder and knee is less commonly seen, and the wrist, ankle, hands, and feet are rarely involved [1]. HO in TBI cases usually occurs on hemiplegic limbs, whereas occurring in the neurologically noninvolved side is rare [7-10].

Chalidis et al. [3] found that altering the natural course of HO is difficult once it has started $[3,11]$. Therefore, prevention should be emphasized. Unfortunately, predicting or preventing the development of $\mathrm{HO}$ is very difficult [12-13]. Pharmacological interventions or local

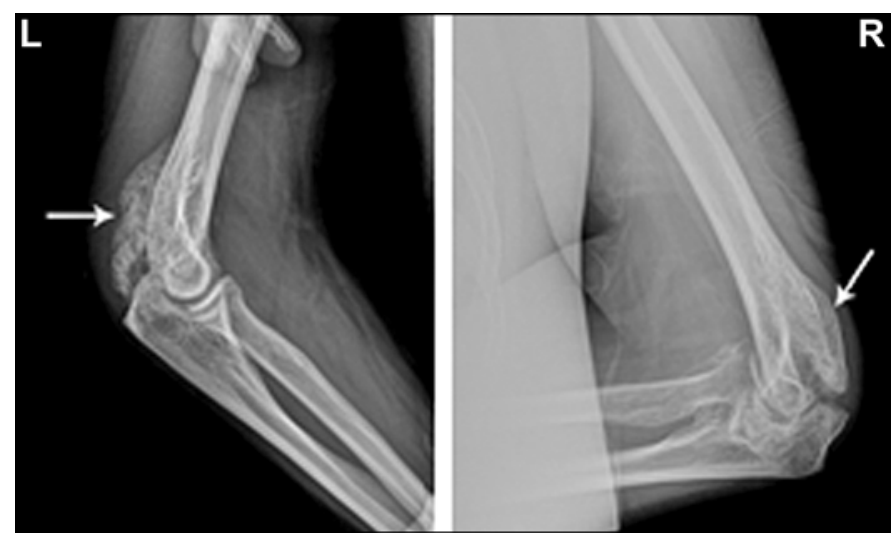

Figure 2.

Lateral radiographies showing heterotopic ossification on posterior aspect of joints in both elbows. $\mathrm{L}=$ left, $\mathrm{R}=$ right. 


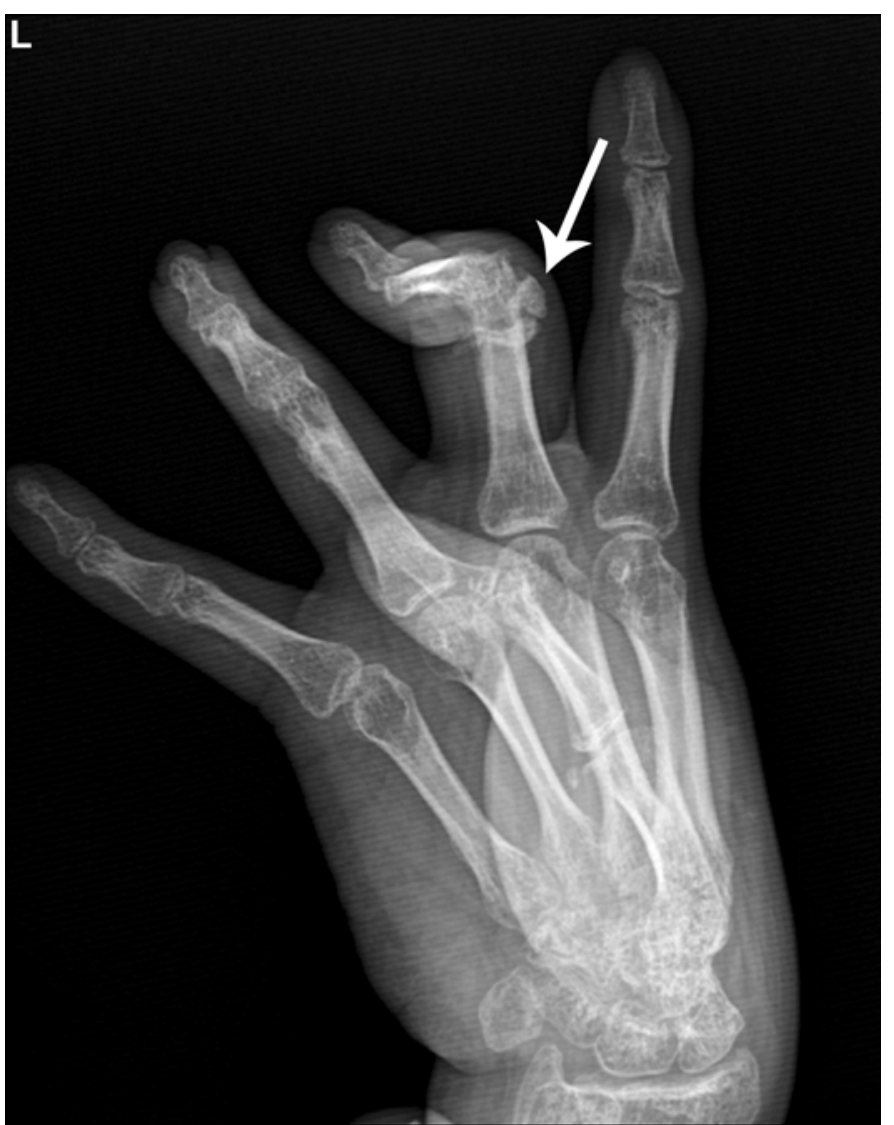

Figure 3.

Hand in prone position showing heterotopic ossification on ventroradial aspect of proximal interphalangeal of left $(L)$ middle finger.

radiation therapy have been recommended as prophylaxis for $\mathrm{HO}$, but the result is uncertain and controversial $[11,14-19]$. We administered oral indomethacin as a routine after each operation because some studies had reported its role in prophylaxis for $\mathrm{HO}$ [20-21].

The traditional trepidation and pessimism regarding surgical excision of heterotopic bone is giving way to a realization that operative treatment is successful in most cases and dramatic functional improvements can be

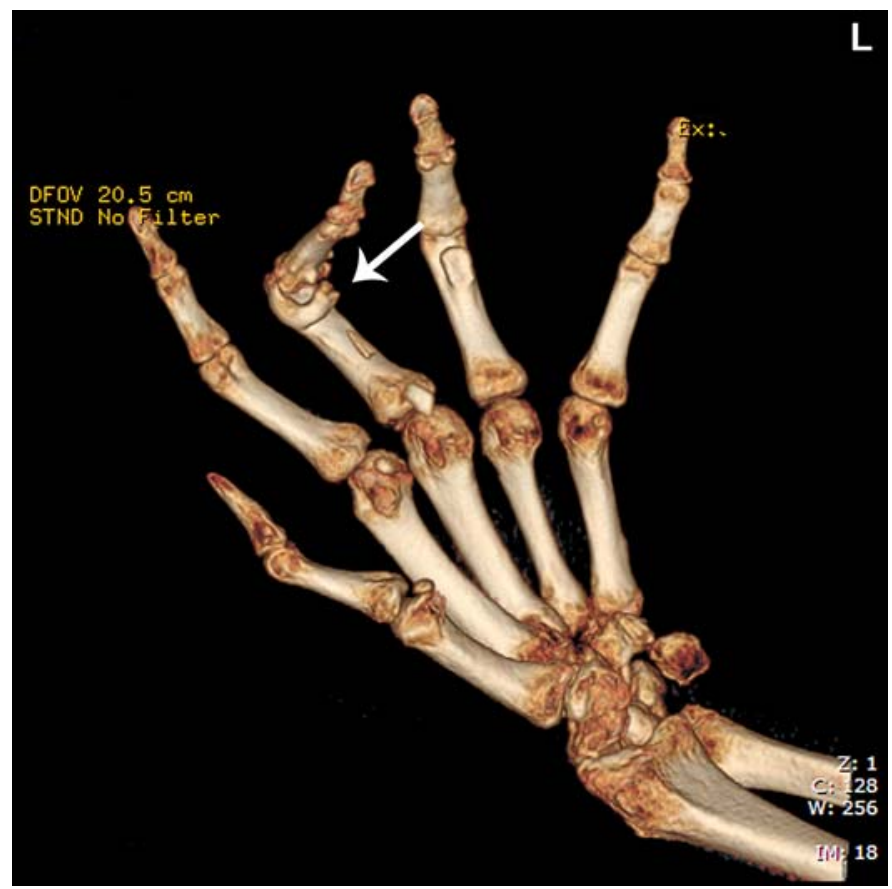

Figure 4.

Three-dimensional computed tomography of hand in supine position clearly delineating extent and location of heterotopic ossification. $L=$ left.

obtained [6,22-26]. Garland recommends time tables for the surgical removal of HO depending on the etiology [27]. The surgical management of HO aims to improve mobility and decrease the complications of immobility, such as pressure ulcers, intractable pain, and impingement of important neurovascular structures. In addition, surgery allows for the patient and caretaker to improve mobility and ease of care, respectively. In the immediate postoperation, continuous passive and active motion in flexion and extension was started to the point of joint resistance and the point of discomfort, and it has been shown to be beneficial in improving eventual ROM $[12,14]$.

Table.

Range of motion (in degrees) of involved joints at last follow-up.

\begin{tabular}{|c|c|c|c|c|c|}
\hline Joint & Flexion & Extension & Abduction & $\begin{array}{l}\text { Internal } \\
\text { Rotation }\end{array}$ & $\begin{array}{l}\text { External } \\
\text { Rotation }\end{array}$ \\
\hline Right Shoulder & 60 & 20 & 45 & 20 & 15 \\
\hline Left Shoulder & 70 & 20 & 70 & 20 & 15 \\
\hline Right Elbow & 100 & 20 & - & - & - \\
\hline Left Elbow & 90 & 30 & - & - & - \\
\hline Proximal Interphalangeal (left middle finger) & 90 & 0 & - & - & - \\
\hline
\end{tabular}



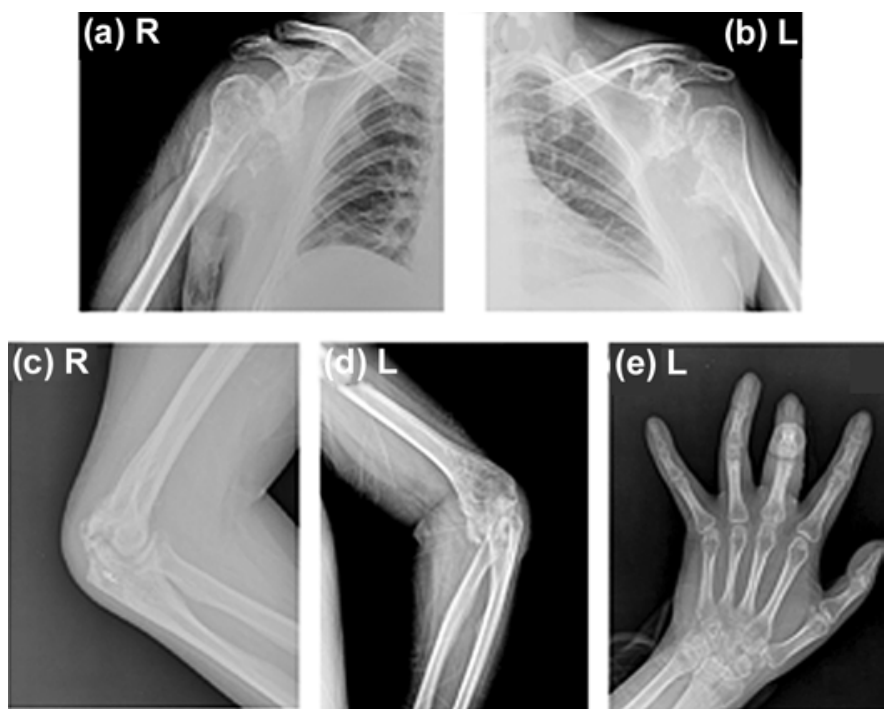

Figure 5.

(a-b) Anteroposterior radiograph of shoulders after surgery showing absence of heterotopic ossification ( $\mathrm{HO}$ ) recurrence. (c-d) Lateral radiographs of elbows after surgery showing absence of $\mathrm{HO}$ recurrence. (e) Radiograph of hand after surgery showing absence of $\mathrm{HO}$ recurrence. $\mathrm{L}=$ left, $\mathrm{R}=$ right.

For the present case, the complete bilateral stiffness of the shoulders and elbows left the patient in a very difficult situation regarding the use of his hands, which severely affected ADLs. Surgical intervention is a very important procedure in the comprehensive rehabilitation management of such cases. The risk of recurrence is increased when a patient must undergo multiple simultaneous operations [28-29]. Therefore, as a precautionary measure, we operated on one joint at a time in the present case.

A rehabilitation program should be started within the first $24 \mathrm{~h}$ after surgery and last for at least $3 \mathrm{wk}$. We believe that the first $3 \mathrm{wk}$ is the "window" to prevent adhesion. For this case, active and passive ROM exercises were encouraged and started on the morning of the first postoperative day within tolerable pain under the care of a physiotherapist. In order to alleviate the spasticity in the limbs, manipulation techniques such as tapping, cold water compress, rubbing, and stretching were used to assist joint exercises.

Studies have shown that arm movement influences the postural stability during walking and sitting [30-31]. Reduced arm swing is a factor leading to poor balance control during walking [32]. Tung et al. found that the upper limbs play an important role in affecting frontal plane balance control [33]. All of these studies confirmed that human walking involves coordinated movements of all four limbs. In the present case, the patient felt he could walk more stably with swinging arms after the treatment despite the spasticity. A limitation of the present report is that a balance test was not performed before and after the management, so an objective comparison could not be made.

The recurrence of $\mathrm{HO}$ is a complicated problem. In this case, no recurrence occurred at the 2 yr follow-up. The good outcome may be related to the maturity of $\mathrm{HO}$, operation on one joint at a time, sufficient wound drains, the emphasis on gentle manipulation, and oral indomethacin. However, this requires further research.

\section{CONCLUSIONS}

In conclusion, this is the first report on the comprehensive rehabilitation management of a case with five joints of stiffness secondary to $\mathrm{HO}$ in bilateral upper limbs after TBI. Obvious improvement in ADLs was achieved. Surgical excision is important in the comprehensive protocol. An individualized rehabilitation program, including therapistassisted gentle exercises, guarantees satisfactory results for such cases.

\section{ACKNOWLEDGMENTS}

\section{Author Contributions:}

Study concept and design: K. Liu, H. Min.

Drafting of manuscript: X. Han.

Acquisition of data: R. Gu.

Financial Disclosures: The authors have declared that no competing interests exist.

Funding/Support: This material was based on work supported by the China Rehabilitation Research Center (grant 2010-Q2).

Institutional Review: This study was approved by the Medical Ethics Committee of China Rehabilitation Research Center and Beijing Boai Hospital.

Participant Follow-Up: The authors plan to inform the participant of the publication of this study.

\section{REFERENCES}

1. Cipriano CA, Pill SG, Keenan MA. Heterotopic ossification following traumatic brain injury and spinal cord injury. J Am Acad Orthop Surg. 2009;17(11):689-97. [PMID:19880679] 
2. Simonsen LL, Sonne-Holm S, Krasheninnikoff M, Engberg AW. Symptomatic heterotopic ossification after very severe traumatic brain injury in 114 patients: Incidence and risk factors. Injury. 2007;38(10):1146-50. [PMID:17572418] http://dx.doi.org/10.1016/j.injury.2007.03.019

3. Chalidis B, Stengel D, Giannoudis PV. Early excision and late excision of heterotopic ossification after traumatic brain injury are equivalent: A systematic review of the literature. J Neurotrauma. 2007;24(11):1675-86. [PMID:18001198] http://dx.doi.org/10.1089/neu.2007.0342

4. Shehab D, Elgazzar AH, Collier BD. Heterotopic ossification. J Nucl Med. 2002;43(3):346-53. [PMID:11884494]

5. Akman S, Sönmez MM, Ertürer RE, Seçkin MF, Kara A, Oztürk I. The results of surgical treatment for posttraumatic heterotopic ossification and ankylosis of the elbow. Acta Orthop Traumatol Turc. 2010;44(3):206-11.

[PMID:21088461] http://dx.doi.org/10.3944/AOTT.2010.2441

6. Baldwin K, Hosalkar HS, Donegan DJ, Rendon N, Ramsey M, Keenan MA. Surgical resection of heterotopic bone about the elbow: An institutional experience with traumatic and neurologic etiologies. J Hand Surg Am. 2011;36(5): 798-803. [PMID:21458925] http://dx.doi.org/10.1016/j.jhsa.2011.01.015

7. Cifu DX, Kreutzer JS, Slater DN, Taylor N. Rehabilitation after traumatic brain injury. In: Braddom RL, editor. Physical medicine \& rehabilitation. 3rd ed. Philadelphia (PA): Saunders Elsevier; 2007. p. 1133-75.

8. Garland DE, Blum CE, Waters RL. Periarticular heterotopic ossification in head-injured adults. Incidence and location. J Bone Joint Surg Am. 1980;62(7):1143-46. [PMID:6776126]

9. Kocaağa Z, Bal S, Gurgan A. Hemiplegia and heterotopic ossification on the non-paretic extremity: A case report. J Rehabil Med. 2007;39(6):500-502. [PMID:17624486]

10. Kesikburun S, Omaç ÖK, Yaşar E, Hazneci B, Alaca R. Severe heterotopic ossification in the non-affected limbs of a hemiplegic patient with traumatic brain injury. Brain Inj. 2011;25(1):127-29. [PMID:21142825] http://dx.doi.org/10.3109/02699052.2010.536198

11. McAuliffe JA, Wolfson AH. Early excision of heterotopic ossification about the elbow followed by radiation therapy. J Bone Joint Surg Am. 1997;79(5):749-55. [PMID:9160948]

12. Ippolito E, Formisano R, Farsetti P, Caterini R, Penta F. Excision for the treatment of periarticular ossification of the knee in patients who have a traumatic brain injury. $\mathrm{J}$ Bone Joint Surg Am. 1999;81(6):783-89. [PMID:10391543]

13. Pape HC, Marsh S, Morley JR, Krettek C, Giannoudis PV. Current concepts in the development of heterotopic ossification. J Bone Joint Surg Br. 2004;86(6):783-87.

\section{[PMID: 15330014]}

http://dx.doi.org/10.1302/0301-620X.86B6.15356

14. Ippolito E, Formisano R, Caterini R, Farsetti P, Penta F. Operative treatment of heterotopic hip ossification in patients with coma after brain injury. Clin Orthop Relat Res. 1999;365(365):130-38. [PMID:10627697]

15. Charnley G, Judet T, Garreau de Loubresse C, Mollaret O. Excision of heterotopic ossification around the knee following brain injury. Injury. 1996;27(2):125-28. [PMID:8730387] http://dx.doi.org/10.1016/0020-1383(95)00180-8

16. de Palma L, Rapali S, Paladini P, Ventura A. Elbow heterotopic ossification in head-trauma patients: Diagnosis and treatment. Orthopedics. 2002;25(6):665-68.

\section{[PMID:12083577]}

17. Rumi MN, Deol GS, Bergandi JA, Singapuri KP, Pellegrini VD Jr. Optimal timing of preoperative radiation for prophylaxis against heterotopic ossification. A rabbit hip model. J Bone Joint Surg Am. 2005;87(2):366-73.

[PMID:15687161] http://dx.doi.org/10.2106/JBJS.C.00974

18. Balboni TA, Gobezie R, Mamon HJ. Heterotopic ossification: Pathophysiology, clinical features, and the role of radiotherapy for prophylaxis. Int J Radiat Oncol Biol Phys. 2006;65(5):1289-99. [PMID:16863921] http://dx.doi.org/10.1016/j.jirobp.2006.03.053

19. Hoff P, Rakow A, Gaber T, Hahne M, Sentürk U, Strehl C, Fangradt M, Schmidt-Bleek K, Huscher D, Winkler T, Matziolis D, Matziolis G, Badakhshi H, Burmester GR, Duda GN, Perka C, Buttgereit F. Preoperative irradiation for the prevention of heterotopic ossification induces local inflammation in humans. Bone. 2013;55(1):93-101.

[PMID:23571050]

http://dx.doi.org/10.1016/j.bone.2013.03.020

20. Banovac K, Williams JM, Patrick LD, Haniff YM. Prevention of heterotopic ossification after spinal cord injury with indomethacin. Spinal Cord. 2001;39(7):370-74.

[PMID:11464310]

http://dx.doi.org/10.1038/sj.sc.3101166

21. Banovac K, Williams JM, Patrick LD, Levi A. Prevention of heterotopic ossification after spinal cord injury with COX-2 selective inhibitor (rofecoxib). Spinal Cord. 2004; 42(12):707-10. [PMID:15179440] http://dx.doi.org/10.1038/sj.sc.3101628

22. Moore TJ. Functional outcome following surgical excision of heterotopic ossification in patients with traumatic brain injury. J Orthop Trauma. 1993;7(1):11-14.

[PMID:8433193]

http://dx.doi.org/10.1097/00005131-199302000-00003

23. Devnani AS. Management of heterotopic ossification affecting both hips and knees. Singapore Med J. 2008;49(6):501-4. [PMID:18581026] 
24. Mitsionis GI, Lykissas MG, Kalos N, Paschos N, Beris AE, Georgoulis AD, Xenakis TA. Functional outcome after excision of heterotopic ossification about the knee in ICU patients. Int Orthop. 2009;33(6):1619-25.

[PMID:18641984] http://dx.doi.org/10.1007/s00264-008-0618-8

25. Jayasundara JA, Punchihewa GL, de Alwis DS, Renuka MD. Short-term outcome after resection of neurogenic heterotopic ossification around the hips and elbow following encephalitis. Singapore Med J. 2012;53(5):e97-100.

[PMID:22584991]

26. Fuller DA, Mani US, Keenan MA. Heterotopic ossification of the shoulder in patients with traumatic brain injury.

J Shoulder Elbow Surg. 2013;22(1):52-56.

[PMID:22652064]

http://dx.doi.org/10.1016/j.jse.2012.01.028

27. Garland DE. A clinical perspective on common forms of acquired heterotopic ossification. Clin Orthop Relat Res. 1991;263(263):13-29. [PMID:1899635]

28. Garland DE, Hanscom DA, Keenan MA, Smith C, Moore T. Resection of heterotopic ossification in the adult with head trauma. J Bone Joint Surg Am. 1985;67(8):1261-69. [PMID:3932363]

29. Spencer RF. Heterotopic ossification in a finger following head injury. J Hand Surg [Br]. 1991;16(2):217-18. [PMID:1905742] http://dx.doi.org/10.1016/0266-7681(91)90182-N

30. Grangeon M, Gagnon D, Gauthier C, Jacquemin G, Masani K, Popovic MR. Effects of upper limb positions and weight support roles on quasi-static seated postural stability in individuals with spinal cord injury. Gait Posture. 2012;
36(3):572-79. [PMID:22771157]

http://dx.doi.org/10.1016/j.gaitpost.2012.05.021

31. Stephenson JL, De Serres SJ, Lamontagne A. The effect of arm movements on the lower limb during gait after a stroke. Gait Posture. 2010;31(1):109-15.

[PMID:19854654]

http://dx.doi.org/10.1016/j.gaitpost.2009.09.008

32. Acar M, Karatas GK. The effect of arm sling on balance in patients with hemiplegia. Gait Posture. 2010;32(4):641-44. [PMID:20888770] http://dx.doi.org/10.1016/j.gaitpost.2010.09.008

33. Tung JY, Gage WH, Zabjek KF, Maki BE, McIlroy WE. Frontal plane standing balance with an ambulation aid: Upper limb biomechanics. J Biomech. 2011;44(8):1466-70. [PMID:21458816]

http://dx.doi.org/10.1016/j.jbiomech.2011.03.015

Submitted for publication March 25, 2013. Accepted in revised form October 10, 2013.

This article and any supplementary material should be cited as follows:

Min H, Liu K, Han X, Gu R. Management of multijoint stiffness of bilateral upper limbs secondary to heterotopic ossification: Case report and literature review. J Rehabil Res Dev. 2014;51(3):497-502. http://dx.doi.org/10.1682/JRRD.2013.03.0073

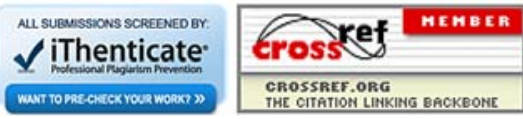

